\title{
Impact of Exercise-based Cardiac Rehabilitation on In-stent Restenosis with Different Generations of Drug Eluting Stent
}

\author{
Chul Kim, M.D., Ph.D., Hee Eun Choi, M.D., Byung Ok Kim, M.D., Ph.D ., Min Ho Lim, M.D. \\ Departments of Rehabilitation Medicine, 'Cardiology, \\ Sanggye Paik Hospital, Inje University College of Medicine, Seoul 139-707, Korea
}

\begin{abstract}
Objective To compare the rate of restenosis between a cardiac rehabilitation (CR) group and a control group within three different generations of drug eluting stents (DES).

Method Patients who received DES due to an acute coronary syndrome were included. They were divided into a $\mathrm{CR}$ group and a control group. The CR group received six to eight weeks of early cardiac rehabilitation program in a hospital setting, and sustained a self-exercise program for six months in a community. The control group was instructed to exercise by themselves after leaving the hospital. Nine months after the first onset of disease, we implemented a coronary angiography and compared the two groups. In addition, we divided the patients into three subgroups according to the generation of DES, and compared the rate of restenosis between the CR group and control group within these three subgroups.

Results At 9 months, in-stent restenosis, measured as an in-segment late luminal loss (LLL) of the stented coronary area, was smaller in the CR group $(n=52) 0.16 \pm 0.42 \mathrm{~mm}$ compared to the control group $(\mathrm{n}=51) 0.39 \pm 0.78$ $\mathrm{mm}(\mathrm{p}<0.05)$. A reduction of LLL in the CR group compared to the control group was consistent among the three different generations of DES.

Conclusion The CR program is strongly associated with a significant reduction in LLL in the stented coronary segments, regardless of the generation of DES.
\end{abstract}

Key Words Coronary restenosis, Drug eluting stent, Exercise, Rehabilitation

\section{INTRODUCTION}

Received December 7, 2011; Accepted February 23, 2012 Corresponding author: Min Ho Lim

Department of Rehabilitation Medicine, Sanggye Paik Hospital, Inje University College of Medicine, 761-1, Sangye 7-dong, Nowon-gu, Seoul 139-707, Korea

Tel: +82-2-950-1134, Fax: +82-2-935-3076, E-mail: ckim@paik.ac.kr (c) This is an open-access article distributed under the terms of the Creative Commons Attribution Non-Commercial License (http:// creativecommons.org/licenses/by-nc/3.0) which permits unrestricted noncommercial use, distribution, and reproduction in any medium, provided the original work is properly cited.

Copyright () 2012 by Korean Academy of Rehabilitation Medicine
Regular exercise is known to be effective for the primary and secondary preventions of cardiovascular disease. ${ }^{1,2}$ Studies have reported that a systematic cardiac rehabilitation combined with regular exercise improved cardiopulmonary function, psychosocial state, and quality of life of the patient, decreased the all-cause and cardiovascular mortality by $20-30 \%,^{3-5}$ and delayed the progression or reduced the severity of artherosclerosis. ${ }^{6,7}$ Primary percutaneous coronary intervention (PCI) was effective 
for long- and short-term treatment of patients with acute myocardial infarction, ${ }^{8}$ though considerable recurrence and restenosis were reported. ${ }^{9}$ Although the rate of stent thrombosis occurrence within 12 months after PCI was reported to be approximately $1 \%$ because of a new dualantiplatelet therapy regimen, the mortality due to stent thrombosis was $20-40 \% .{ }^{1}$ As such, to reduce the incidence of restenosis in the stented coronary area, a drugeluting stent (DES) was introduced, and studies have reported that the rate of restenosis was significantly lower in the DES group than in the bare metal stent group..$^{10,11}$ In the DES, however, late stent thrombosis occurred 1-12 months after the intervention due to delayed strut endothelialization and potential prothrombotic characteristics. ${ }^{1}$ Thus, safety continues to be a problem. ${ }^{12}$

Coronary sclerosis and its risk factors interrupt the vasolidation produced by the vascular endothelial cells, and change the relationship between the vascular wall, inflammatory cells, and platelets. ${ }^{13}$ The growth of tunica intima is related to the late luminal loss after the implantation of the stent, ${ }^{14}$ and with the inflammatory reaction caused by persistent shear stress ${ }^{15}$ and the vascular damage that accompanies increased c-reactive protein (CRP).${ }^{16}$ The endothelial dysfunction that occurs after the implantation of the stent is an independent predictor of initial restenosis. ${ }^{17}$

Based on these findings, studies have revealed that 6 months of regular exercise after the insertion of the stent reduced the late luminal loss in the stented area. ${ }^{18} \mathrm{In}$ addition, an increased peak $\mathrm{VO}_{2}$ could improve exercise capability and regular exercise improved endotheliumdependent vasodilatation through the activation of endothelial nitric oxide synthase. ${ }^{18}$ In another study examining patients with stable coronary artery stenosis $(\leq 75 \%$ diameter stenosis), regular exercise without coronary artery intervention increased the maximum oxygen consumption $\left(\mathrm{VO}_{2} \mathrm{max}\right)$ and thus, reduced the inflammatory reaction. This is unlike coronary intervention without regular exercise. In the two-year follow-up period of the patients, there were fewer cardiac events in the regularexercise-without-coronary intervention group. ${ }^{19}$

It is known that in patients with coronary artery diseases, the implantation of a DES reduces the rate of restenosis, compared with the insertion of a bare metal stent. However, there have not been any controlled studies that compared the extent of restenosis after the implantation of the DES in the cardiac rehabilitation group and in the non-cardiac rehabilitation group. There are also no published studies that have compared the extent of the restenosis of different types of DESs based on the findings that cardiac rehabilitation reduced the rate of restenosis after the insertion of a stent. As such, this study compared the extents of the in-stent restenosis between the cardiac rehabilitation group and the control group of patients who had received various types of DESs.

\section{MATERIALS AND METHODS}

\section{Subjects}

Patients who were admitted to this hospital for acute coronary syndrome (ACS) and successfully underwent percutaneous coronary intervention (PCI) using a DES were included in this study. The criterion for a successful PCI was a $<30 \%$ reduction in residual diameter stenosis. ${ }^{20}$ Patients with a history of cardiovascular disease, cerebrovascular disease, or neuromusculoskeletal disease that may disturb the exercise program were excluded from this study. All subjects were asked to participate in the cardiac rehabilitation program through training on the need for cardiac rehabilitation and the contents of the program. The patients who wanted to participate in the cardiac rehabilitation program in a hospital setting were assigned to the cardiac rehabilitation group, and those who did not want to participate in the program, to the control group. Previous studies performed by this author have shown that the most common cause of non-participation in the cardiac rehabilitation program was a lack of awareness (78\%), followed by doubt regarding the effect of the program, lack of time, anxiety, prohibitive program cost, difficulty in movement, distance from the patient's home to the hospital, and transportation difficulty. In particular, the causes of discontinuance of the cardiac rehabilitation program were a lack of awareness and the regional and socioeconomic conditions of the patient. ${ }^{21}$

\section{Methods}

The patients in the cardiac rehabilitation group underwent a pretest that included an exercise stress test at the cardiac rehabilitation clinic of our hospital after they were discharged following a coronary artery intervention. On average, they began performing cardiac rehabilitation exercise 14 days after the onset of the disease.

For the exercise stress test, the symptom-limited exercise test based on the modified Bruce protocol was used. 
Based on the maximum and resting heart rates that were measured in the exercise stress test, the heart rate reserve was calculated, and the exercise intensity was set at the target heart rate (40-85\% of the heart rate reserve). The objective markers that included the electrocardiographic change, heart rate, and blood pressure (BP) were monitored, and the patient's subjective symptoms during the exercise were monitored based on Borg's rate of perceived exertion (RPE), a subjective marker. Each training session comprised a warm-up (10 min), main exercise (30 $\mathrm{min})$, and cool-down (10 $\mathrm{min})$. The main exercise included a treadmill course ( $8 \mathrm{~min})$, rest ( $3 \mathrm{~min})$, ergometer measurement ( $8 \mathrm{~min})$, rest ( $3 \mathrm{~min})$, and another treadmill course $(8 \mathrm{~min})$. The patients were asked to perform the 50-min exercise program three times a week for 6-8 weeks (for a total of 18-24 sessions), and all the patients and their families were educated on the risk factors, drug therapy, and smoking cessation, and given obesity and nutrition consultations. A blood test, body mass index measurement, BP measurement, and exercise consultation were performed at one- to three-month intervals to ensure that the patients managed their risk factors of coronary artery disease. After 6-8 weeks of the in-hospital exercise program, an exercise stress test was performed to determine the target heart rate and the RPE, based on which another new exercise was prescribed and the patients were asked to continue doing the newly prescribed exercise in a community setting for up to nine months after the onset of the disease. The control group that did not participate in the cardiac rehabilitation program received basic training on the management of risk factors after the onset of the acute coronary artery syndrome risk factors and on exercising; and the patients were left to carry out the risk factor management and exercises on their own.

The patients in the cardiac rehabilitation and control groups were followed and all received a drug prescription for up to nine months at the cardiac medicine and rehabilitation clinics as outpatients. Both groups underwent coronary angiography with the same cardiologist both at the time of their initial PCI and nine months after the onset of the disease. Based on the groups' minimal lumen diameter (MLD), their diameter stenosis \% was measured, and their late luminal loss (LLL) and luminal loss (LL \%) at the time of the onset of the disease and at nine months were compared. The criterion for restenosis was $>50 \%$ of the in-stent diameter stenosis. ${ }^{22}$ Next, the pa- tients were further divided into the first-generation stent group (Taxus and Cypher), the second-generation stent group (Endeavor Sprint and Endeavor Resolute), and the third-generation stent group (Xience and Promus), and their in-stent diameter stenosis values were compared using the same markers as those between the three subgroups in the cardiac rehabilitation and control groups.

\section{Statistical analysis}

For statistical analysis, the SAS Enterprise Guide 4.1 (4.1.0.471) was used. A Wilcoxon rank sum test was used to compare the cardiac rehabilitation and control groups in terms of their sexes, ages, ST segment elevation myocardial infarctions, non-ST segment elevation myocardial infarctions, proportions of patients with unstable angina, hypertension, diabetes, numbers of cases of dyslipidemia, smoking habits, body mass indexes, left ventricular ejection fractions (LVEF) at the start of their cardiac rehabilitation, and drug used, as well as their HbAlc values at the start of and nine months after their cardiac rehabilitation. The Wilcoxon rank sum test was also used to compare the number and locations of the affected vessels, number of stents used, and number of stents in each generation (further classified according to the types of DES) in the cardiac rehabilitation and control groups. The response values were ranked using a Wilcoxon rank sum test, which involved multiple comparisons of the results of the Kruskal-Wallis test. The rankings were applied to a one-way ANOVA multiple comparison to compare the diameter stenoses with the three types of stents.

\section{RESULTS}

\section{Baseline characteristics of the subjects}

A total of 103 patients were included in this study, and they were classified into the cardiac rehabilitation group $(n=52)$ and the control group $(n=51)$. There was no difference in the sex ratios between the cardiac rehabilitation group (male $=35$ and female $=17$ ) and the control group (male $=41$ and female $=10$ ).

The mean age did not significantly differ between the groups: 61.08 years in the cardiac rehabilitation group and 64 years in the control group. The numbers of patients with acute coronary syndromes classified into ST-elevation myocardial infarction, non-ST-elevation myocardial infarction, and unstable angina did not differ 
between the two groups.

The numbers and locations of the affected vessels did not differ between the two groups. The LVEF and risk factors (hypertension, diabetes, hyperlipidemia, smoking history, and body mass index) at the start of the cardiac rehabilitation and the types of drugs given did not differ between the two groups. Fifty-four stents were used in the cardiac rehabilitation group and 51 in the control group. The number of first-generation (Taxus and Cipher), second-generation (Endeavor Sprint, Coroflex, and Pico Elite), and third-generation (Endeavor Resolute, Promus, and Xince V) stents that were used did not differ between the two groups (Tables 1,2).

Comparison of the in-stent restenoses of the cardiac rehabilitation group and the control group nine months after their coronary artery intervention

Nine months after the coronary artery intervention, the coronary angiography did not reveal a significant difference in the minimal luminal diameters between the two groups. However, there was a significant difference in the late luminal losses between the two groups $(0.16 \pm 0.42$ $\mathrm{mm}$ in the cardiac rehabilitation group and $0.39 \pm 0.78$ $\mathrm{mm}$ in the control group) and a significant difference in the late losses between the two groups $(1.2 \pm 19.5 \%$ in the cardiac rehabilitation group and $13.2 \pm 25.5 \%$ in the control group) ( $\mathrm{p}=0.002)$.

The residual diameter stenosis (\%DS), an indication of the extent of the restenosis, was lower in the cardiac rehabilitation group $(12.5 \pm 19.5 \%)$ than in the control group (13.2 $\pm 25.5 \%)$, though the difference was not significant (Table 3).
Comparison of the in-stent restenosis with other factors

Nine-month follow-up data revealed after the coronary artery intervention, the number of patients with in-stent restenosis did not significantly differ between the rehabilitation group $(n=1,1.9 \%)$ and the control group $(n=8$, $15.7 \%$ ). After the onset of the disease, the LVEF was high-

Table 1. Characteristics of Subjects

\begin{tabular}{lccc}
\hline & $\begin{array}{c}\text { CR } \\
(\mathbf{n = 5 2})\end{array}$ & $\begin{array}{c}\text { Control } \\
(\mathbf{n = 5 1 )}\end{array}$ & p-value \\
\hline Male/Female & $35 / 17$ & $41 / 10$ & 0.13 \\
Age (year) & 61.08 & 64 & 0.12 \\
Diagnosis (STEMI/ & $18 / 10 / 24$ & $16 / 10 / 25$ & 0.84 \\
$\quad$ NSTEMI/UA) & & & \\
Hypertension & $32(61.5 \%)$ & $30(58.8 \%)$ & 0.78 \\
Diabetes & $10(19.2 \%)$ & $18(35.3 \%)$ & 0.07 \\
Hyperlipidemia & $42(80.8 \%)$ & $34(67 \%)$ & 0.10 \\
Smoking (Current/Ex/ & $23 / 9 / 20$ & $28 / 13 / 10$ & 0.10 \\
$\quad$ Never) & & & \\
BMI & 24.55 & 24.86 & 0.96 \\
LVEF (\%) & 58.25 & 57.8 & 0.79 \\
Acetylsalicylic acid & 52 & 49 & 0.15 \\
Clopidogrel & 52 & 51 & 1.00 \\
Beta blocker & 32 & 22 & 0.90 \\
\hline ACEI/ARB & 36 & 35 & 0.95 \\
Statin & 50 & 48 & 0.63 \\
\hline
\end{tabular}

CR: Cardiac rehabilitation, STEMI: ST elevation myocardial infarction, NSTEMI: Non-ST elevation myocardial infarction, UA: Unstable angina, BMI: Body mass index, LVEF: Left ventricular ejection fraction, ACEI: Angiotensin-1 conversion enzyme inhibitor, ARB: Angiotensin-2 receptor blocker

Table 2. Angiographic and Procedural Characteristics

\begin{tabular}{lcc}
\hline & CR (n=52) & Control (n=51) \\
\hline $\begin{array}{l}\text { Number of diseased vessels } \\
\text { 1/2/3 }\end{array}$ & $32 / 16 / 4$ & $38 / 8 / 5$ \\
Target vessel artery & & 0.43 \\
$\quad$ LAD/LCX/RCA & $39 / 2 / 11$ & $29 / 6 / 16$ \\
Number of stents & 54 & 51 \\
DES type & & 0.13 \\
$1^{\text {st }}$ generation (Taxus/Cypher) & $16(9 / 7)$ & $22(14 / 8)$ \\
$2^{\text {nd }}$ generation (Endeavor sprinter/Coroflex/Pico elite) & $25(20 / 4 / 1)$ & $13(7 / 2 / 4)$ \\
$3^{\text {rd }}$ generation (Endeavor resolute/Promus/Xince V) & $13(4 / 3 / 6)$ & $16(11 / 2 / 3)$ \\
\hline
\end{tabular}

CR: Cardiac rehabilitation, LAD: Left anterior descending, LCX: Left circumflex, RCA: Right coronary artery, DES: Drug eluting stent 
Table 3. QCA Results at 9 Months

\begin{tabular}{lccc}
\hline & CR (n=52) & Control (n=51) & p-value \\
\hline Lesion length (mm) & $19.5 \pm 6.1$ & $20.8 \pm 6.4$ & 0.25 \\
Reference diameter (mm) & $2.7 \pm 0.5$ & $2.8 \pm 0.5$ & 0.63 \\
Minimal luminal diameter (mm) & $2.3 \pm 0.5$ & $2.1 \pm 0.7$ & 0.13 \\
Late luminal loss (mm) & $0.16 \pm 0.42$ & $0.39 \pm 0.78$ & 0.013 \\
Residual diameter stenosis (\%DS) & & \\
Before PCI & $92.9 \pm 6.6$ & $90.4 \pm 9.4$ & 0.21 \\
Immediately after PCI & $11.4 \pm 13.8$ & $8.5 \pm 15.3$ & 0.28 \\
9 months after PCI & $12.5 \pm 21.3$ & $21.9 \pm 23.2$ & 0.052 \\
\hline Late loss (\%) & $1.2 \pm 19.5$ & $13.2 \pm 25.5$ & 0.002 \\
\hline
\end{tabular}

QCA: Quantitative coronary angiography, CR: Cardiac rehabilitation, PCI: Percutaneous coronary intervention

Table 4. In-Stent Restenosis and Other Features at 9 Months

\begin{tabular}{lccc}
\hline & $\begin{array}{c}\text { CR Group } \\
(\mathbf{n = 5 2 )}\end{array}$ & $\begin{array}{c}\text { Control } \\
(\mathbf{n = 5 1 )}\end{array}$ & p-value \\
\hline Number of ISR & 1 & 8 & 0.014 \\
Rate of restenosis (\%) & 1.9 & 15.7 & \\
LVEF at entry & $58.24 \pm 10.19$ & $57.80 \pm 10.28$ & 0.79 \\
LVEF at 9 months & $64.29 \pm 14.15$ & $59.85 \pm 11.46$ & 0.07 \\
\hline
\end{tabular}

CR: Cardiac rehabilitation, ISR: In-stent restenosis, LVEF: Left ventricular ejection fraction

er in the cardiac rehabilitation group than in the control group, and the HbAlc level, a marker of diabetes control, was lower in the cardiac rehabilitation group, though in both cases, they were not significant $(\mathrm{p}<0.063)$ (Table 4$)$.

Comparison of restenoses based on different generations of DESs

The numbers of first-, second-, and third-generation stents that were used in the cardiac rehabilitation group were 16,25 , and 13 , respectively, and in the control group, 22, 13, and 16, respectively.

In the cardiac rehabilitation group that performed the rehabilitation for nine months and in the control group, there was no difference in the diameter restenoses of the three subgroups that received the three different types of DESs (Table 5).

\section{DISCUSSION}

Although advances in medical technology have gradually reduced mortality due to coronary artery disease, the prevalence of the disease continues to rise each year. ${ }^{23,24}$
It was reported that for patients who had survived, particularly those who had experienced myocardial infarction, their quality of life would decrease due to their decreased ability to be active in daily life. ${ }^{25}$ As hospital stay has shortened due to advances in coronary artery intervention and the development of novel drugs, ${ }^{26}$ the need to control possible complications and risk factors of recurrence has emerged.

Cardiac rehabilitation is considered particularly important because it is known to improve the exercise capability of patients with coronary artery disease and in the secondary prevention of the disease through a comprehensive program that consists of an individualized exercise program based on the exercise prescription, nutrition consultation, a smoking cessation program, drug therapy, and weight control. ${ }^{27}$

Post-coronary artery intervention restenosis has a high medical cost and an increased risk of revascularization. ${ }^{18}$ Both the bare metal stent and the DES have the possible issue of stent thrombosis and restenosis, and thus, may result in the recurrence of myocardial infarction and death. ${ }^{28}$ In particular, it was reported that a DES could result in hypersensitivity to polymers and delayed endothelialization in the stented area, ${ }^{28}$ and that DM, among the predictors of thrombosis, decreased the effect of antiplatelet agents, such as aspirin and clopidogrel. ${ }^{29}$ In this study, of the eight patients with restenosis in the control group, three had DM. In addition, a study had reported that regular exercise reduced the inflammatory reaction related to the in-stent restenosis in patients with heart failure or CAD. ${ }^{18}$ Thus, it is believed that various relevant factors that may induce restenosis should be controlled with an active cardiac rehabilitation program for patients 
Table 5. QCA Results According to DES Type at 9 Months

\begin{tabular}{|c|c|c|c|c|c|c|}
\hline & \multicolumn{3}{|c|}{$C R(n=52)$} & \multicolumn{3}{|c|}{ Control $(n=51)$} \\
\hline & $1^{\text {st }} \mathbf{G}(\mathrm{n}=16)$ & $2^{\text {nd }} G(n=25)$ & $3^{\text {rd }} G(n=13)$ & $1^{\text {st }} \mathbf{G}(\mathrm{n}=22)$ & $2^{\text {nd }} G(n=13)$ & $3^{\text {rd }} G(n=16)$ \\
\hline $\mathrm{LL}(\mathrm{mm})$ & $21.3 \pm 7.2$ & $17.2 \pm 4.5$ & $20.0 \pm 5.6$ & $22.2 \pm 6.9$ & $21.8 \pm 5.6$ & $17.7 \pm 5.6$ \\
\hline $\mathrm{RD}(\mathrm{mm})$ & $2.8 \pm 0.5$ & $2.8 \pm 0.5$ & $2.6 \pm 0.5$ & $2.7 \pm 0.3$ & $2.9 \pm 0.7$ & $2.9 \pm 0.6$ \\
\hline $\operatorname{MLD}(\mathrm{mm})$ & $2.4 \pm 0.4$ & $2.4 \pm 0.4$ & $2.3 \pm 0.4$ & $2.0 \pm 0.7$ & $2.2 \pm 0.7$ & $2.2 \pm 0.6$ \\
\hline \multicolumn{7}{|l|}{$\% \mathrm{DS}$} \\
\hline Before PCI & $91.3 \pm 8.9$ & $94.7 \pm 4.7$ & $92.0 \pm 7.5$ & $92.1 \pm 9.6$ & $88.5 \pm 9.4$ & $89.9 \pm 9.5$ \\
\hline After PCI & $13.1 \pm 11.1$ & $13.1 \pm 11.1$ & $9.9 \pm 13.1$ & $7.8 \pm 14.1$ & $9.3 \pm 17.2$ & $8.9 \pm 16.1$ \\
\hline 9 months & $11.5 \pm 23.7$ & $11.5 \pm 23.7$ & $13.4 \pm 11.3$ & $24.5 \pm 23.7$ & $19.2 \pm 26.2$ & $21.0 \pm 28.7$ \\
\hline LL (\%) & $-1.6 \pm 22.6$ & $-2.2 \pm 15.3$ & $3.5 \pm 11.1$ & $16.6 \pm 26.3$ & $9.9 \pm 22.5$ & $12.0 \pm 28.7$ \\
\hline
\end{tabular}

CR: Cardiac rehabilitation, QCA: Quantitative coronary angiography, DES: Drug eluting stent, G: Generation, LL: Lesion length, RD: Residual diameter, MLD: Minimal luminal diameter, DS: Diameter stenosis, PCI: Percutaneous coronary intervention, LL (\%): Late loss

who had undergone coronary artery intervention. This study was performed with patients who had a DES implanted, and we investigated the influence of cardiac rehabilitation-based regular exercise on post-stent implantation restenosis in patients who had a DES implant. A study that compared two types of first-generation DESs, a SES (sirolimus-eluting stent) and a PES (paclitaxel-eluting stent), showed that SES was superior to PES in reducing late $\operatorname{loss}^{10}$ and another study reported that there was no difference between SES and PES with regard to late loss. ${ }^{26}$ This study compared the late restenoses of first-, second-, and third-generation stents, and found no difference in the restenoses of the three generations in the cardiac rehabilitation and control groups.

Recently, however, it was reported that the risk of very late thrombosis increased by $0.1-0.6 \%$ each year in the DES-implanted group (unlike in the bare-metal-stentimplanted group $)^{30}$ and that interest in DES-related mortality and late stent thrombosis is increasing. ${ }^{26,30}$ As such, studies are underway to compare mortality and the recurrence of myocardial infarction in relation to DES. Therefore, a study that compares the diameter restenoses after a short- and long-term follow-up is needed. One study that has demonstrated the relationship between a high level of activity and the proportion of cardiovascular diseases has shown that 3-6 months of high-intensity exercise reduced in-stent restenosis in patients who had undergone coronary artery intervention. The high-intensity exercise was related to the activation of nitric oxide (NO) synthase (due to the improved vascular endothelial cells), the decreased CRP that promotes arteriosclerosis, and the reduced endothelin-1 production that exacerbates the endothelial cell function. ${ }^{18}$ Likewise, in this study, late luminal loss and late loss were significantly lower in the cardiac rehabilitation group than in the control group, and the number of patients with in-stent restenosis significantly differed between the two groups ( $\mathrm{n}=1$ and 8 , respectively). Steady cardiac rehabilitation-based exercise capability measurement can assist in the early detection of coronary artery restenosis ${ }^{31}$ and the assessment of the exercise capability through regular measurement of the $\mathrm{VO}_{2}$ consumption can be the most robust and independent predictor of cardiovascular disease mortality. ${ }^{18}$ Thus, regular cardiac rehabilitation and exercise capability measurements are considered important for patients who had undergone coronary artery intervention. The limitations of this study are: first, the decision to participate in the cardiac rehabilitation program was left to the patients to decide, and those with a high risk of cardiac crisis were not assigned to the community setting exercise group. Thus, it was impossible to perform a random selection comparative analysis. Second, the difference in the management of various risk factors, such as hypertension, diabetes, hyperlipidemia, obesity, and smoking between the two groups was not clearly identified. Third, as the study period was nine months, follow-up time was short. Further studies with long-term comparison of the restenosis of the cardiac rehabilitation group with that of the control group and between different-generation DESs are needed, as are studies on the mortality and morbidity of coronary artery disease. Fourth, this study did not have a large sample, which was also a limitation in the other 
studies that compared restenosis after the insertion of DESs. In particular, interpreting the results of the studies that compared the diameter restenosis of different generations of DESs is still debatable. Thus, it is believed that randomized controlled studies with more subjects will achieve more objective outcomes.

\section{CONCLUSION}

Cardiac rehabilitation significantly reduced in-stent late luminal loss, late loss, and percent diameter stenosis, regardless of the type of the ever-advancing DESs. This indicates that cardiac rehabilitation can significantly delay the progression of in-stent restenosis.

Therefore, we expect that adequate exercise through cardiac rehabilitation can reduce the rate of intervention repetition and mortality in patients with cardiovascular disease or who had undergone a coronary artery intervention.

\section{REFERENCES}

1. Taylor RS, Brown A, Ebrahim S, Jolliffe J, Noorani H, Rees K, Skidmore B, Stone JA, Thompson DR, Oldridge $\mathrm{N}$. Exercise-based rehabilitation for patients with coronary heart disease: systematic review and meta-analysis of randomized controlled trials. Am J Med 2004; 116: 682-692

2. Piepoli MF, Davos C, Francis DP, Coats AJ. Exercise training meta-analysis of trials in patients with chronic heart failure (ExTraMATCH). BMJ 2004; 328: 189

3. O'Connor GT, Buring JE, Yusuf S, Goldhaber SZ, Olmstead EM, Paffenbarger RS Jr, Hennekens CH. An overview of randomized trials of rehabilitation with exercise after myocardial infarction. Circulation 1989; 80: 234-244

4. Dugmore LD, Tipson RJ, Phillips MH, Flint EJ, Stentiford NH, Bone MF, Littler WA. Changes in cardiopulmonary fitness, psychological wellbeing, quality of life, and vocational status following a 12 month cardiac exercise rehabilitation programme. Heart 1999; 81: 359-366

5. Witt BJ, Jacobsen SJ, Weston SA, Killian JM, Meverden RA, Allison TG, Reeder GS, Roger VL. Cardiac rehabilitation after myocardial infarction in the community. J Am Coll Cardiol 2004; 44: 988-996
6. Niebauer J, Hambrecht R, Velich T, Hauer K, Marburger C, Kalberer B, Weiss C, von Hodenberg E, Schlierf G, Schuler G, et al. Attenuated progression of coronary artery disease after 6 years of multifactorial risk intervention: role of physical exercise. Circulation 1997; 96: 2534-2541

7. Haskell WL, Alderman EL, Fair JM, Maron DJ, Mackey SF, Superko HR, Williams PT, Johnstone LM, Champagne MA, Krauss RM, et al. Effects of intensive multiple risk factor reduction on coronary atherosclerosis and clinical cardiac events in men and women with coronary artery disease. The Stanford Coronary Risk Intervention Project (SCRIP). Circulation 1994; 89: 975-990

8. Keeley EC, Boura JA, Grines CL. Primary angioplasty versus intravenous thrombolytic therapy for acute myocardial infarction: a quantitative review of 23 randomised trials. Lancet 2003; 361: 13-20

9. Cannan CR, Yeh W, Kelsey SF, Cohen HA, Detre K, Williams DO. Incidence and predictors of target vessel revascularization following percutaneous transluminal coronary angioplasty: a report from the National Heart, Lung, and Blood Institute Percutaneous Transluminal Coronary Angioplasty Registry. Am J Cardiol 1999; 84: 170-175

10. Di Lorenzo E, Sauro R, Varricchio A, Capasso M, Lanzillo T, Manganelli F, Mariello C, Siano F, Pagliuca MR, Stanco G, et al. Benefits of drug-eluting stents as compared to bare metal stent in ST-segment elevation myocardial infarction: four year results of the PaclitAxel or Sirolimus-Eluting stent vs bare metal stent in primary angioplasty (PASEO) randomized trial. Am Heart J 2009; 158: e43-50

11. Greenhalgh J, Hockenhull J, Rao N, Dundar Y, Dickson RC, Bagust A. Drug-eluting stents versus bare metal stents for angina or acute coronary syndromes. Cochrane Database Syst Rev 2010; 5: CD004587

12. Morice MC, Serruys PW, Sousa JE, Fajadet J, Ban Hayashi E, Perin M, Colombo A, Schuler G, Barragan P, Guagliumi G, et al. A randomized comparison of a sirolimus-eluting stent with a standard stent for coronary revascularization. N Engl J Med 2002; 346: 17731780

13. Zeiher AM, Drexler H, Wollschlaeger H, Just H. Endothelial dysfunction of the coronary microvasculature is associated with impaired coronary blood flow regu- 
lation in patients with early atherosclerosis. Circulation 1991; 84: 1984-1992

14. Post MJ, de Smet BJ, van der Helm Y, Borst C, Kuntz RE. Arterial remodeling after balloon angioplasty or stenting in an atherosclerotic experimental model. Circulation 1997; 96: 996-1003

15. Wentzel JJ, Krams R, Schuurbiers JC, Oomen JA, Kloet J, van Der Giessen WJ, Serruys PW, Slager CJ. Relationship between neointimal thickness and shear stress after Wallstent implantation in human coronary arteries. Circulation 2001; 103: 1740-1745

16. Saleh N, Tornvall P. Serum C-reactive protein response to percutaneous coronary intervention in patients with unstable or stable angina pectoris is associated with the risk of clinical restenosis. Atherosclerosis 2007; 195: 374-378

17. Piatti P, Di Mario C, Monti LD, Fragasso G, Sgura F, Caumo A, Setola E, Lucotti P, Galluccio E, Ronchi C, et al. Association of insulin resistance, hyperleptinemia, and impaired nitric oxide release with in-stent restenosis in patients undergoing coronary stenting. Circulation 2003; 108: 2074-2081

18. Munk PS, Staal EM, Butt N, Isaksen K, Larsen AI. High-intensity interval training may reduce in-stent restenosis following percutaneous coronary intervention with stent implantation. A randomized controlled trial evaluating the relationship to endothelial function and inflammation. Am Heart J 2009; 158: 734-741

19. Walther C, Mobius-Winklera S, Linke A, Bruegel M, Thiery J, Schuler G, Halbrecht R. Regular exercise training compared with percutaneous intervention leads to a reduction of inflammatory markers and cardiovascular events in patients with coronary artery disease. Eur J Cardiovasc Prev Rehabil 2008, 15: 107112

20. Belardinelli R, Paolini I, Cianci G, Piva R, Georgiou D, Purcaro A. Exercise training intervention after coronary angioplasty: the ETICA trial. J Am Coll Cardiol 2001; 37: 1891-1900

21. Kim C, Lim HS, Ahn JK, Bang IK, Lee SM, Kim YJ. The reasons that cardiac patients did not participate in and drop out from the cardiac rehabilitation program. J Korean Acad Rehab Med 2002; 26: 790-796

22. Thiele H, Neumann-Schniedewind P, Jacobs S, Bou- driot E, Walther T, Mohr FW, Schuler G, Falk V. Randomized comparison of minimally invasive direct coronary artery bypass surgery versus sirolimus-eluting stenting in isolated proximal left anterior descending coronary artery stenosis. J Am Coll Cardiol 2009; 53: 2324-2331

23. Law MR, Watt HC, Wald NJ. The underlying risk of death after myocardial infarction in the absence of treatment. Arch Intern Med 2002; 162: 2405-2410

24. The World Health Report 1997- conquering suffering, enriching humanity. World Health Forum 1997; 18: 248-260

25. Brezinka V, Kittel F. Psychosocial factors of coronary heart disease in women: a review. Soc Sci Med 1996; 42: 1351-1365

26. Lee JY, Park DW, Yun SC, Lee SW, Kim YH, Lee CW, Hong MK, Park SW, Park SJ. Long-term clinical outcomes of sirolimus- versus paclitaxel-eluting stents for patients with unprotected left main coronary artery disease: analysis of the MAIN-COMPARE (revascularization for unprotected left main coronary angioplasty versus surgical revascularization) registry. J Am Coll Cardiol 2009; 54: 853-859

27. Izawa K, Hirano Y, Yamada S, Oka K, Omiya K, Iijima S. Improvement in physiological outcomes and healthrelated quality of life following cardiac rehabilitation in patients with acute myocardial infarction. Circ J 2004; 68: 315-320

28. Wernick MH, Jeremias A, Carrozza JP. Drug-eluting stents and stent thrombosis: a cause for concern? Coron Artery Dis 2006; 17:661-665

29. Lemesle G, Delhaye C, Bonello L, de Labriolle A, Waksman R, Pichard A. Stent thrombosis in 2008: definition, predictors, prognosis and treatment. Arch Cardiovasc Dis 2008; 101: 769-777

30. Dos Santos A, Peirano JD, Bastianello MJ, Calvino RO. Very late drug-eluting stent thrombosis post-exercise myocardial perfusion SPECT. J Nucl Cardiol 2010; 17: 928-933

31. Lan C, Chen SY, Chiu SF, Hsu CJ, Lai JS, Kuan PL. Poor functional recovery may indicate restenosis in patients after coronary angioplasty. Arch Phys Med Rehabil 2003; 84: 1023-1027 